\title{
RADIO ECHO SOUNDING: ABSORPTION AND SCATTERING BY WATER INCLUSION AND ICE LENSES
}

\author{
By B. M. Ewen Smith \\ (British Antarctic Survey, Scott Polar Research Institute, Cambridge) \\ and S. Evans \\ (Scott Polar Research Institute, Cambridge)
}

\begin{abstract}
The absorption of radio waves propagating through naturally occurring waters varies greatly with the electrical conductivity. Glacier melt water is very transparent and the attenuation by melt water layers is due to reflexion of power, whereas the attenuation of sea-water layers is due to absorption. The attenuation of soaked firn is usually prohibitive if the liquid is brine but it should not be a serious obstacle to radio echo strength if the liquid is rain-water or melt water. However, the magnitude of the scattered power can become greater than that from continuous (bedrock) reflectors if the size of the irregularities in the medium is large (approaching the radio wavelength in ice). Echo power formulae show that ice lenses may have the most serious effect and that low radio frequencies will be necessary to combat this.
\end{abstract}

RÉsumé. Sondage par écho radio : absorption el dispersion par des inclusions d'eau et des lentilles de glace. L'absorption des ondes radio se propageant à travers les eaux naturelles varie beaucoup avec leur conductivité électrique. L'eau de fusion des glaciers est très transparente et l'atténuation par les niveaux d'eau fondue est dûe à la réflexion de l'énergie, tandis que l'atténuation des niveaux d'eau de mer est dûe à l'absorption. L'atténuation du névé mouillé est d'ordinaire prohibitive si le liquide est de la saumure mais ce ne serait pas un sérieux obstacle à la puissance de l'écho radio si le liquide est de l'eau de pluie ou de l'eau de fonte. Cependant, l'importance de l'énergie dispersée peut devenir supérieure à celle issue de réflecteurs continus (le lit rocheux) si la dimension des irrégularités dans le milieu traversé est grande (approchant la longueur d'onde de l'émission radio dans la glace). Les formules de l'énergie de l'écho radio montrent que les lentilles de glace auront l'effet le plus sérieux et qu'il sera nécessaire d'employer de basses fréquences radio pour les combattre.

Zusammenfassung. Radar-Echolotung: Absorption und Zerstreutung durch Wassereinschlüsse und Eislinsen. Die Absorption von Radar-Wellen beim Durchgang durch natürliche Wasservorkommen schwankt beträchtlich mit der elektrischen Leitfähigkeit. Gletscherschmelzwasser ist sehr durchlässig und die Dämpfung durch Schmelzwasserschichten wird durch Reflexion von Energie verursacht, während die Dämpfung durch Meerwasserschichten auf Absorption zurückgeht. Die Dämpfung in durchtränktem Firn führt gewöhnlich zu völliger Auslöschung, wenn die Flüssigkeit Salzwasser ist; aber die Stärke des Radarechos sollte nicht ernstlich geschwächt werden, wenn die Flüssigkeit Regen- oder Schmelzwasser ist. Jedoch kann die Menge der zerstreuten Energie grösser werden als die von zusammenhängenden Reflektoren (Felsgrund) zurückgeworfene, wenn die Ausdehnung der Unregelmässigkeiten im Medium gross ist (annähernd gleich der Radarwellenlänge in Eis). Formeln für die Echoenergie zeigen, dass Eislinsen den schwerwiegendsten Einfluss ausüben und dass niedrige Radarfrequenzen nötig sind, um dem zu begegnen.

\section{INTRODUCTION}

Radio echo sounding in polar glaciers is now a well established technique but work on temperate glaciers has been sporadic and inconclusive. Complicating factors have arisen because of the smaller scale of the detail desired, that is to say, better areal resolution on the glacier bottom, better range (depth) resolution, and shallower minimum depths, often coupled with a requirement for more accurate positioning on the glacier surface than is usual in the polar situation. Possibly these considerations have obscured the most important requirement: to obtain first of all an unambiguous bottom echo, however poor in resolution, and to gain an understanding of those properties of the medium of propagation which are important in temperate glaciers. Armed with this understanding one may then consider ways in which the resolution, or the general convenience of the system might be improved.

We suppose that it is the presence of liquid water, rather than the ice fabric, the impurity content, or the temperature, which makes for the essential difference from the polar glacier, as far as radio propagation is concerned, and we have considered the effect on absorption and scattering (and thus on wanted to unwanted signal ratio) for various idealized models of water distribution and for various waters. It may be noted in passing that the scattered 
signal, which is the "unwanted" signal at present, may, with greater understanding, be of considerable use in hydrological investigations in the future. We are looking particularly towards the problem of temperate glaciers because of the practical need for the technique to develop in that direction but it is worth mentioning that the initial stimulation came from polar radio-echo records. On the Ward Hunt Ice Shelf in Canada and on George VI Sound, Antarctica, pools of melt water form on the surface in summer but strong bottom echoes have been recorded in both places. On the other hand, in some Antarctic ice shelves a thin irregular layer of liquid brine forms at about sea-level (Heine, r968); in these conditions it seems that the bottom echo is usually obscured. The models which we consider include a range of water conductivities and layer thicknesses, followed by models of permeable snow saturated with water and permeable snow containing lenses of solid ice. The attenuation of the forward wave and the strength of the scattered signal are computed and some results are found to be steeply dependent on radio wavelength and size of irregularity in the medium.

\section{Electromagnetic PARAmeters For WATER, ice, AND SNOW}

The basic equations of radio wave propagation may be found in engineering or physics textbooks and it is usual to make separate approximations for moderately good conductors $(\sigma / \omega \epsilon \gg \mathrm{I}$, see following paragraph) and slightly lossy dielectrics $(\sigma / \omega \epsilon \ll \mathrm{I})$. However in this paper we may need to consider intermediate cases, such as low salinity sea-water or very impure rain-water, and neither of these approximations has been made in the graphical results given here.

The medium is characterized by two parameters: conductivity, $\sigma$, a real quantity, and permittivity, $\epsilon$, also real. (Alternative parameters such as $\epsilon^{\prime \prime}, \tan \delta$, and $\sigma^{\prime \prime}$ are not used in this paper). We assume that the relative magnetic permeability, $\mu^{\prime}=\mathrm{I}$ and we have $\mu_{0}=4 \pi \times \mathrm{IO}^{-7} \mathrm{~m}^{-1}$; the dielectric permittivity $\epsilon=\epsilon^{\prime} \epsilon_{0}$ and $\epsilon_{0}=10^{-9} / 36 \pi \mathrm{F} \mathrm{m}^{-1}$. $\mathscr{E}_{0}$ is the amplitude of the electric field strength in $\mathrm{V} \mathrm{m}^{-1}$ and $\omega$ is the angular frequency in $\mathrm{Hz}$. Following the usual notation, the propagation constant, $\gamma=\alpha+\mathrm{j} \beta$ defines the variation of wave amplitude and phase with distance $x$ according to $\exp (-\gamma x)$. Thus the attenuation is $8.68 \alpha \mathrm{dB} \mathrm{m}^{-1}$ and the wavelength in the medium is $2 \pi / \beta$.

We have

$$
\begin{aligned}
& \alpha^{2}=\left[\left\{\mathrm{I}+(\sigma / \omega \epsilon)^{2}\right\}^{\frac{1}{2}}-\mathrm{I}\right] \omega^{2} \mu \epsilon / 2, \\
& \beta^{2}=\left[\left\{\mathrm{I}+(\sigma / \omega \epsilon)^{2}\right\}^{\frac{1}{2}}+\mathrm{I}\right] \omega^{2} \mu \epsilon / 2 .
\end{aligned}
$$

The instrinsic impedance of a medium is

$$
\eta=\{\mu / \epsilon(\mathrm{I}+\sigma / \mathrm{j} \omega \epsilon)\}^{\frac{1}{2}} .
$$

The amplitude reflexion coefficient for normal incidence on the boundary between two media, I and 2, is $\left|\rho_{\mathrm{I} 2}\right|$ and the transmission coefficient is $\left|\tau_{12}\right|$ where

$$
\rho_{12}=\left(\eta_{2}-\eta_{1}\right) /\left(\eta_{2}+\eta_{1}\right) \text { and } \tau_{12}=2 \eta_{2} /\left(\eta_{2}+\eta_{1}\right) \text {. }
$$

The power flow within any one medium is given by

$$
p=\frac{1}{2} \mathscr{E}_{0}^{2} \mathscr{R}(\mathrm{I} / \eta) \text {. }
$$

There are three "raw materials": ice, water at $0^{\circ} \mathrm{C}$, and air, and various mixtures of the three will be discussed.

\section{Water}

The permittivity of water varies slightly with impurity concentration, but the conductivity varies over many orders of magnitude: several examples are given in Table I. 
TAble I. The a.c. Conductivity and Relative permittivity of ice AND Various Waters

\begin{tabular}{|c|c|c|c|}
\hline & $\epsilon^{\prime}$ & $\begin{array}{c}\sigma \\
\Omega^{-1} \mathrm{~m}^{-1}\end{array}$ & \\
\hline 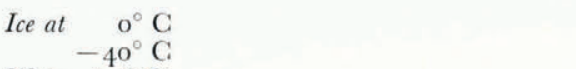 & $\begin{array}{l}3.24 \pm 0.03 \\
3.20 \pm 0.03\end{array}$ & see Figure $I$ & Paren (unpublished) \\
\hline Water at $\mathrm{O}^{\circ} \mathrm{C}$ & & & \\
\hline Pure & 86 & $3.6 \times 10^{-6}$ & Hasted (196I) \\
\hline Distilled & 86 & $\mathrm{I} \times \mathrm{IO}^{-4}$ & (in equilibrium with atmosphere) \\
\hline Temperate glacier melt & 86 & $2 \times 10^{-4}$ & Gorham (1958) \\
\hline Polar ice melt & 86 & 2 to $8 \times 10^{-4}$ & Paren and Walker (1971) \\
\hline Rainwater (Norway) most probable extremes & $\begin{array}{l}80 \\
80\end{array}$ & 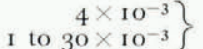 & Egner and Eriksson (1955) \\
\hline Brine of salinity $s$ in parts per I ooo & $<80$ & $9 \times 10^{-2} s$ & Bialek $\left([1967]\right.$, p. $\left.3^{19}\right)$ \\
\hline Sea-water, $s=32 \%$ & 77 & 2.9 & Hasted (196i) \\
\hline
\end{tabular}

Ice

The permittivity of ice is constant, with sufficient accuracy for our purpose (see Table I), but the conductivity must take account of both temperature and impurity concentration. There are three ranges of impurity concentration - pure ice, polar ice, and sea ice - which are best considered separately. By pure ice we mean purity equal to, or higher than, distilled water in equilibrium with the atmosphere. The d.c. conductivity of ice is very sensitive to impurity concentration and it has been found that in situ measurements of d.c. conductivity in temperate glaciers are the same as for pure ice (less than $\mathrm{IO}^{-6} \Omega^{-1} \mathrm{~m}^{-1}$ ) (Röthlisberger, I 967), probably because the impurities have been flushed out of the glacier (Nye and Frank, in press). The a.c. conductivity of ice, independent of frequency between 0.5 and $500 \mathrm{MHz}$, is much greater than the d.c. component because of the audio-frequency relaxation spectrum. Paren (unpublished) gives the following accurate empirical relation for the a.c. conductivity of pure ice:

$$
\sigma=4.6 \times \mathrm{IO}^{-5} \exp -\left[\frac{E}{R}\left(\frac{\mathrm{I}}{T}-\frac{\mathrm{I}}{T_{\mathrm{o}}}\right)\right] \Omega^{-1} \mathrm{~m}^{-1}
$$

where $E=55 \mathrm{~kJ} \mathrm{~mol}^{-1}$ for pure ice, $R=8.4 \mathrm{~J} \mathrm{~mol}^{-1} \mathrm{~K}^{-1}$, and $T_{0}=273 \mathrm{~K}$.

Most polar ice, on the other hand, conforms to the behaviour of "solubility-limit" ice as described by Paren and Walker (I97I). The total impurity content in polar conditions is usually somewhat higher than the equilibrium solubility for solid solution within the ice grain; the excess impurity lies in the triple junctions of the grains and, because of the geometry, makes negligible contribution to the bulk conductivity. Below $-10^{\circ} \mathrm{C}$ the same formula, Equation (5), may be used for the conductivity of polar ice but $E=25 \mathrm{~kJ} \mathrm{~mol}^{-1}$ at the solubility limit. Above $-10^{\circ} \mathrm{C}$ both contributions to the conductivity are of comparable magnitude and they reinforce one another, reaching $6 \times \mathrm{Io}^{-5} \Omega^{-1} \mathrm{~m}^{-1}$ at $\mathrm{o}^{\circ} \mathrm{C}$.

Figure I shows these relations graphically. It is very satisfactory that the curve for polar ice, derived from laboratory measurements on many different ice cores, is closely equivalent to the attenuation curve used by Robin and others ( 1969 ) and others, for the calculation of total attenuation from the temperature profile in polar ice sheets. * There are some situations in the polar regions, near to the melting point, where the temperate glacier conductivity is approached, probably due to the flushing mechanism. Robin and others (1969) found $4.5 \mathrm{~dB} / \mathrm{I} 00 \mathrm{~m}$ for ice below I ooo $\mathrm{m}$ surface elevation in Greenland, and Smith (in press) found $4.5 \mathrm{~dB} / \mathrm{I}$ oo $\mathrm{m}$ on the Fuchs piedmont, Adelaide island, Antarctica.

\footnotetext{
* Figure 23 in Robin and others ( 1969 ) has an error in the point at $-\mathrm{I}^{\circ} \mathrm{C}$ on curve w. The ordinate, derived from Westphal's measurements, should be $5.7 \mathrm{~dB}$ per $100 \mathrm{~m}$ instead of $4.9 \mathrm{~dB}$ per $\mathrm{I}$ oo $\mathrm{m}$ as plotted. Curve A, from Auty and Cole, is closely equivalent to the pure ice curve in Figure $\mathrm{I}$ of this paper.
} 
Besides pure ice and "solubility-limit", or polar ice, we should also mention sea ice which is too impure and irregular to conform to simple relations such as given above. In sea ice the dominant term in the total conductivity is due to liquid brine inclusions. Reference should be made to Fujino ( 1967 ) and Addison (1970) for up-to-date experimental values of conductivity.

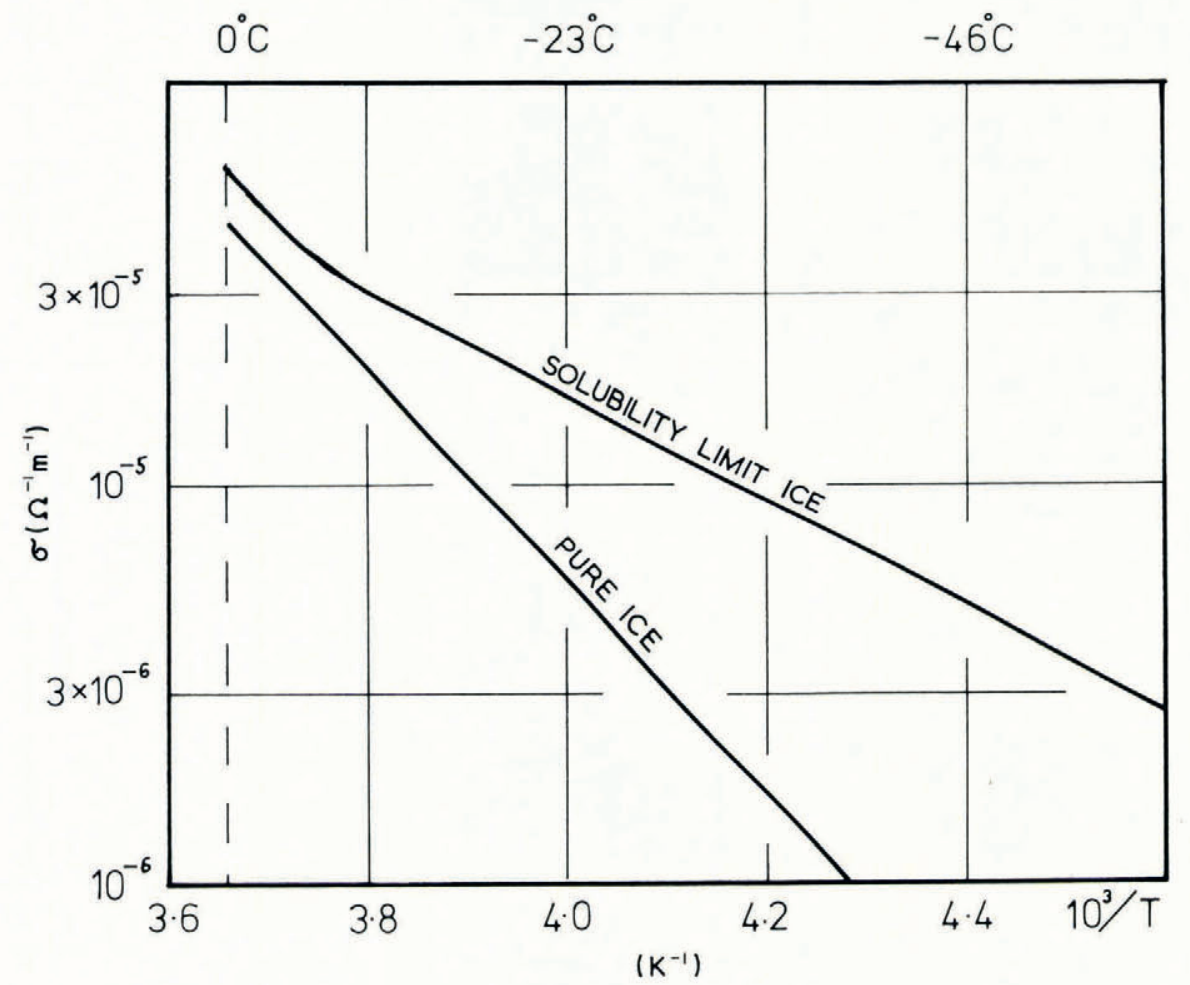

Fig. I. The a.c. conductivity of ice, $\sigma$, in $\Omega^{-1} m^{-1}$ as a function of temperature, $T$, in kelvins. The upper curve (solubility-limit ice) usually applies to polar ice, and the lower curve (pure ice) usually applies to temperate glacier ice.

\section{Mixtures}

The properties of mixtures of dielectrics, with especial application to snow, are considered in detail by Paren (unpublished) to whom reference should be made for the basis of the relations given below.

Dry snow is a mixture of ice and air in proportions which we shall define by the density ratio $\rho^{\prime}=\rho_{\mathrm{d}} / \rho_{\mathrm{i}}$, where the suffices $\mathrm{d}$ and $\mathrm{i}$ refer to dry snow and ice. We have

and

$$
\epsilon_{\mathrm{d}^{\mathrm{I}}}{ }^{1 / 3}-\mathrm{I}=\rho^{\prime}\left(\epsilon_{\mathrm{i}}^{\mathrm{I} / 3}-\mathrm{I}\right)
$$

$$
\sigma_{\mathrm{d}}=\sigma_{\mathrm{i}} \rho^{\prime}\left(0.68+0.3^{2} \rho^{\prime}\right) \text {. }
$$

Another material used in our models is soaked snow, in which all the available air spaces are supposed to be filled with water, forming a network of randomly oriented veins. Then

and

$$
\epsilon_{\mathrm{S}}=\epsilon_{\mathrm{d}}+\frac{1}{3} \epsilon_{\mathrm{W}}\left(\mathrm{I}-\rho^{\prime}\right)
$$

$$
\sigma_{\mathrm{s}}=\sigma_{\mathrm{d}}+\frac{1}{3} \sigma_{\mathrm{w}}\left(\mathrm{I}-\rho^{\prime}\right)
$$

where the suffices $\mathrm{s}$ and $\mathrm{w}$ stand for soaked snow and water. 
Representative numerical values, some of which are used in our calculations, are given in Table I. The values of $\epsilon$ and $\sigma$ are virtually constant with frequency from $\mathrm{I} \mathrm{MHz}$ (sufficiently removed from the relaxation spectrum of ice) to $500 \mathrm{MHz}$ (below the relaxation spectrum of water and the vibration spectrum of ice).

\section{Glacier model}

To access the importance of any additional loss in sensitivity, let us adopt a fixed glacier model as a norm. Deep ice sheets are unlikely to be saturated with water; therefore let us consider a glacier of modest depth, $d=250 \mathrm{~m}$, within $2^{\circ} \mathrm{C}$ of the melting point. In the "slightly lossy dielectric" approximation, the attenuation constant $\alpha=\frac{1}{2} \eta \sigma$ and the intrinsic impedance $\eta=(\mu / \epsilon)^{\frac{1}{2}}$. Substituting $\epsilon=3.2 \epsilon_{0}$ for ice, we find that the attenuation is $9 \times \mathrm{IO}^{4} \sigma_{\mathrm{i}} \mathrm{dB}$ per $\mathrm{I} 00 \mathrm{~m}$. (In water, $\epsilon=86 \epsilon_{0}$, and the attenuation is $\mathrm{I} .8 \times \mathrm{IO}^{4} \sigma_{\mathrm{W}} \mathrm{dB}$ per IOO m.)

For the calculation of power loss due to wave spreading, we use the inverse square law and geometric imaging in a plane reflector. If the observer is at height $h$ (greater than a few wavelengths) above the ice surface, the power varies as $(h+d / n)^{-2}$ where the refractive index of the ice, $n=\sqrt{ } \epsilon^{\prime}=1$.8. We can now calculate the strength of our signal as follows:

$S$ Radio-echo system performance, assume

$G$ Loss due to spreading of wave from either:

(a) half-wave antenna at $35 \mathrm{MHz}$ or

(b) I $\mathrm{m}^{2}$ antenna at $300 \mathrm{MHz}$,

carried on the glacier surface

$R$ Reflexion coefficient (an average value for rock)

$G^{\prime}$ Additional spreading loss if observing from an aircraft at $\mathrm{I}$ ooo $\mathrm{m}$ above the glacier surface

$E$ Without further loss, the signal to noise ratio is

In this model, any effect on sensitivity resulting in a loss of more than about $50 \mathrm{~dB}$ is serious. If the loss is expressed as the attenuation of a particular feature in the ice, traversed twice, then we may adopt $26 \mathrm{~dB}$ for the one-way passage with possible extension to $40 \mathrm{~dB}$ if the ice is floating and the observer on the surface. If the attenuation is distributed throughout the path, we might accept io to $16 \mathrm{~dB}$ per $100 \mathrm{~m}$.

\section{Three LAYer MODEL}

Consider two media of semi-infinite extent separated by a plane layer of a medium of uniform thickness $t$ as shown in Figure 2. We shall evaluate the power reflected by, and transmitted through, the layer in terms of the three intrinsic impedances and the propagation constant of the middle layer ( $\gamma$ contains both the attenuation and phase constants for the middle layer). The incident wave is normal to the interface though it is shown at a small angle in Figure 2 for clarity. The amplitude transmission coefficient $T$ arises from an infinite series of internal reflexions within the layer:

$$
\begin{aligned}
& T=\left|\tau_{12} \tau_{23} \mathrm{e}^{-\gamma t}+\tau_{12} \rho_{23} \rho_{21} \tau_{23} \mathrm{e}^{-3 \gamma t}+\tau_{12} \rho_{23} \rho_{21} \rho_{23} \rho_{21} \tau_{23} \mathrm{e}^{-3 \gamma t}+\ldots\right| \\
& T=\left|\frac{\tau_{12} \tau_{23} \mathrm{e}^{-\gamma t}}{\mathrm{I}-\rho_{21} \rho_{23} \mathrm{e}^{-2 \gamma t}}\right|
\end{aligned}
$$


and similarly for the amplitude reflexion coefficient, $P$ :

$$
P=\left|\rho_{12}+\frac{\tau_{12} \rho_{23} \tau_{21} \mathrm{e}^{-2 \gamma t}}{\mathrm{I}-\rho_{21} \rho_{23} \mathrm{e}^{-2 \gamma t}}\right|
$$

Since the incident and reflected power are in the same medium the power reflexion coefficients, $R_{\mathrm{p}}=P^{2}$, but the transmitted wave is in a different medium from the incident, and the power transmission coefficient is:

$$
T_{\mathrm{p}}=T^{2} \mathscr{R}\left(\mathrm{I} / \eta_{3}\right) / \mathscr{R}\left(\mathrm{I} / \eta_{\mathrm{I}}\right) \text {. }
$$

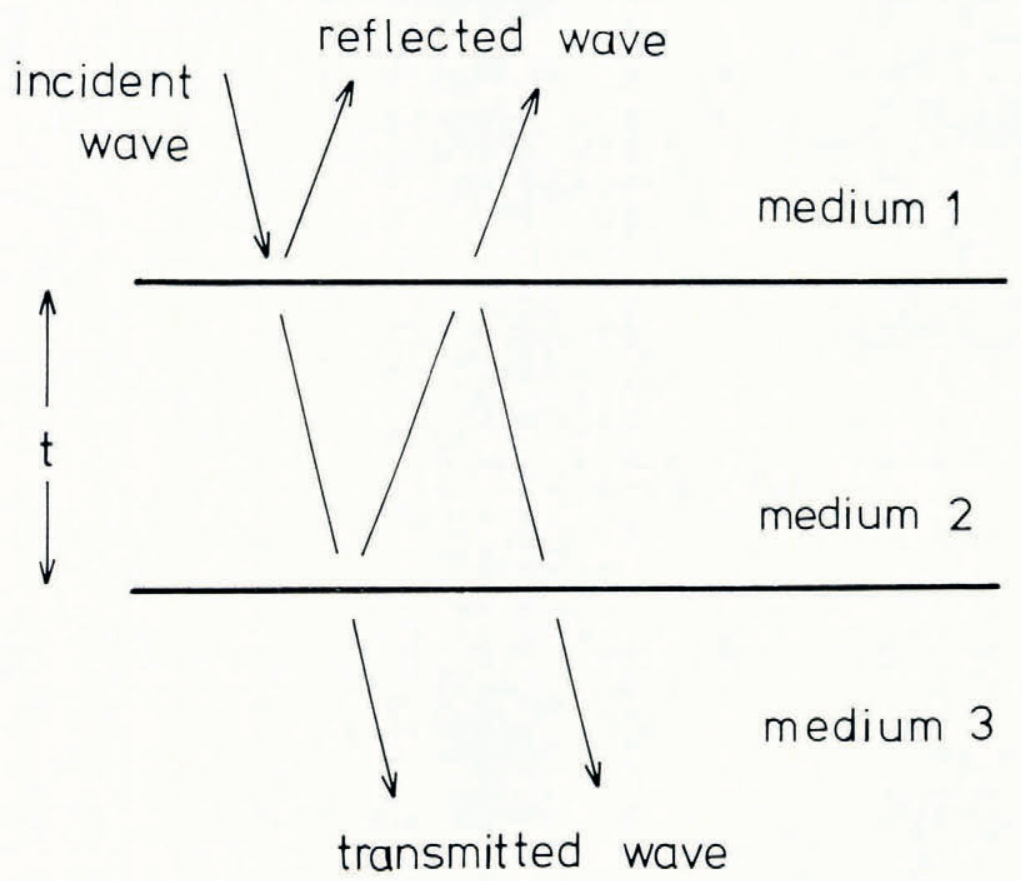

Fig. 2. Three media of propagation having two parallel interfaces, showing the reflected and transmitted waves due to an incident wave close to the normal.

\section{SURFAGE MELT LAYER}

Figure, 3 shows the computed transmission coefficient, at $35 \mathrm{MHz}$, of a layer of water $\left(\sigma=2 \times \mathrm{IO}^{-4}\right)$ lying between air and solid ice. Note the small loss, $0.3 \mathrm{~dB}$, for an infinitely thin layer (the reflexion loss at an air/ice boundary), and note the maximum loss, I I dB, when the water layer is a quarter wavelength thick, remembering that it is the wavelength in water. Finally note the negligible power loss due to water conductivity for water depths of several metres, evident from the constant maximum and minimum values in the interference pattern. Indeed substitution in the "lossy dielectric" approximate formula shows that the attenuation in melt water (3.6 to $\mathrm{I} 4 \mathrm{~dB}$ per $\mathrm{I} 00 \mathrm{~m}$ depending on the conductivity) is of the same order as in ice near the melting point ( 4.5 to $5.7 \mathrm{~dB}$ per $\mathrm{IOO} \mathrm{m}$ ), because of the lower intrinsic impedance of the water. Within the limit of a few metres depth, whilst the absorption is small, the behaviour at other radio-frequencies may be read from Figure 3 by expanding or contracting the thickness scale over at least a decade in either direction. In particular for very thin layers (less than $\lambda_{0} /$ Ioo in thickness, where $\lambda_{0}$ 
is the free-space wavelength) a linear relation may be fitted to the early part of the curve and we find transmission loss $\approx 2.4 f t \mathrm{~dB}$, where $f$ is the frequency in $\mathrm{MHz}$ and $t$ the thickness in metres.

In the summer season on George VI Sound in the Antarctic Peninsula, there are numerous melt pools on the surface of the ice. They occur between lat. $70^{\circ} 40^{\prime} \mathrm{S}$. and lat. $7 \mathrm{I}^{\circ} 5 \mathrm{O}^{\prime} \mathrm{S}$. where the ice is floating and about $200 \mathrm{~m}$ thick. The pools are typically $0.5 \mathrm{~m}$ deep (A. C. Wager, private communication). From an examination of airborne radio echo records (Swithinbank, I968; Smith, in press) there is no evidence that the melt pools cause the bottom echo to be lost. Referring to Figure 3 for the one-way attenuation and remembering that in this situation the signal may be $67 \mathrm{~dB}$ over noise without the pools, we see that the result is not as surprising as it at first appears.

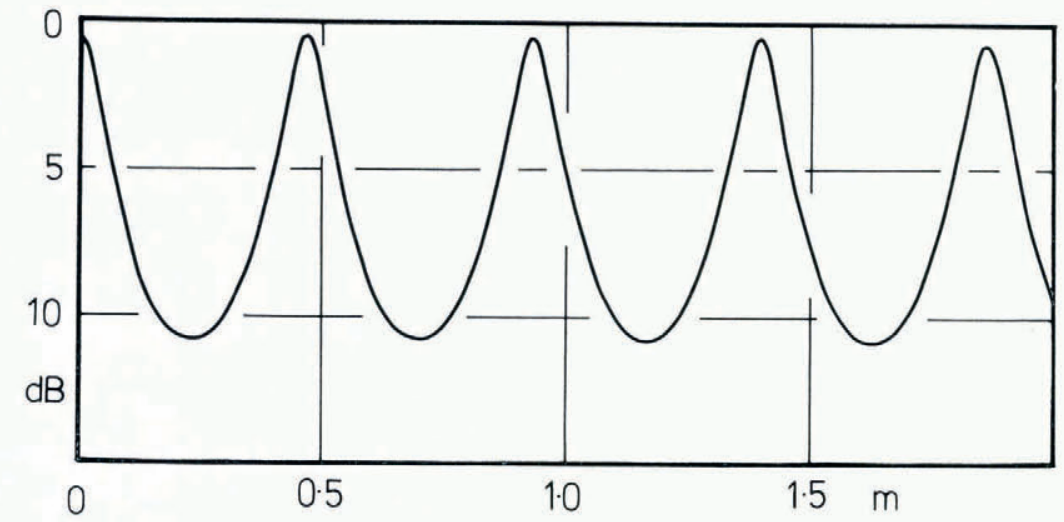

Fig. 3. The attenuation in $d B$ of a $35 \mathrm{MHz}$ wave passing through a layer of melt water $\left(\sigma=2 \times 10^{-4} \Omega^{-1} \mathrm{~m}^{-1}\right)$ lying between air and solid ice, as a function of layer thickness in metres. In practice such a layer is traversed twice and the total attenuation of the echo is twice the ordinate value.

On Roslin Gletscher, Greenland, to take a different example, Davis and Halliday (unpublished) observed a weakening of about $10 \mathrm{~dB}$ in their echo signal at $440 \mathrm{OHz}$ in the daytime, when a film of water was visible on the glacier surface, in contrast to the situation at night. Putting $2.4 \mathrm{ft}=5 \mathrm{~dB}$ attenuation in each direction, a layer of $5 \mathrm{~mm}$ total thickness is required. This is a sharp reminder of the scale of the effect at ultrahigh frequencies. Remember that the maximum for each layer is still I I dB one-way, but that there may be several layers in the line of sight, each contributing about $5 \mathrm{~dB}$, on the average, to the total one-way loss.

What is the error in the measured depth if the water layer is ignored or its presence is unsuspected? The ratio of the radio propagation velocity in water to that in ice is $(3.22 / 86)^{\frac{1}{2}} \approx \mathrm{I} / 5$. In terms of the echo time delay, $\mathrm{I} \mathrm{m}$ depth of water is equivalent to $5 \mathrm{~m}$ of solid ice: this seems likely to be a negligible error in practice because the pools are not very deep.

\section{BRINE PERCOLATION LAYER}

Figure 4 shows that with a highly conducting water layer the situation is quite different. The transmission loss is now dominated by absorption instead of reflexion of power. Curve (a) refers to a sea-water layer $\left(\sigma=2.9 \Omega^{-1} \mathrm{~m}^{-1}\right)$ lying within an almost solid ice medium $\left(\rho=0.8 \mathrm{Mg} \mathrm{m}^{-3}\right)$. The one-way attenuation is $30 \mathrm{~dB}$ for about $\mathrm{ro} \mathrm{cm}$ thickness virtually independent of radio-frequency, but this is a rather unlikely model. In ice shelves it has often been postulated that, in a few places, sea-water percolates horizontally through porous 


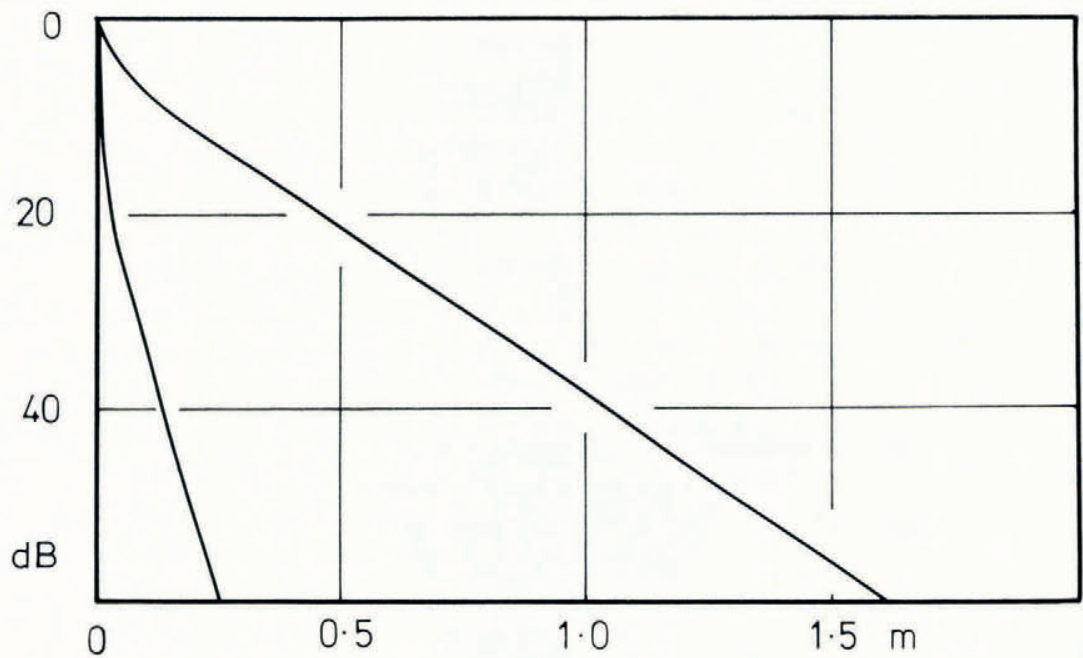

Fig. 4 .

(a) The attenuation in $\mathrm{dB}$ of a $35 \mathrm{MHz}$ wave passing one way through a layer of brine $\left(\sigma=2.9 \Omega^{-\mathrm{I}} \mathrm{m}^{-\mathrm{I}}\right)$ lying within a firn medium $\left(\rho=0.8 \mathrm{Mg} \mathrm{m}^{-3}\right)$, as a function of layer thickness in metres.

(b) The upper curve shows the attenuation in the same circumstances except that the layer consists of brine-soaked firn instead of pure brine.

layers at about sea-level from rifts or from the ice front (Dubrovin, i962; Heine, r968; Swithinbank, I970). The phenomenon is best known in the McMurdo Ice Shelf but it probably occurs in the Wordie Ice Shelf, the Brunt Ice Shelf, the Larsen Ice Shelf, and Wilkins Sound. In all of these places very shallow echoes, at about sea-level occasionally appear with absence of the bottom echo, as illustrated in Figure 5. For curve (b) in Figure 4 we have considered snow of density $\rho=0.8 \mathrm{Mg} \mathrm{m}^{-3}$ to be near the maximum for permeability and evaluated the effect of filling the remaining spaces with sea-water $\left(\sigma=2.9 \Omega^{-1} \mathrm{~m}^{-1}\right)$. It is still true that absorption dominates the loss; therefore the result is insensitive to the radio-frequency and $\mathrm{I} m$ thickness of soaked material causes $38 \mathrm{~dB}$ one-way attenuation. The occultation of the bottom echo is not surprising.

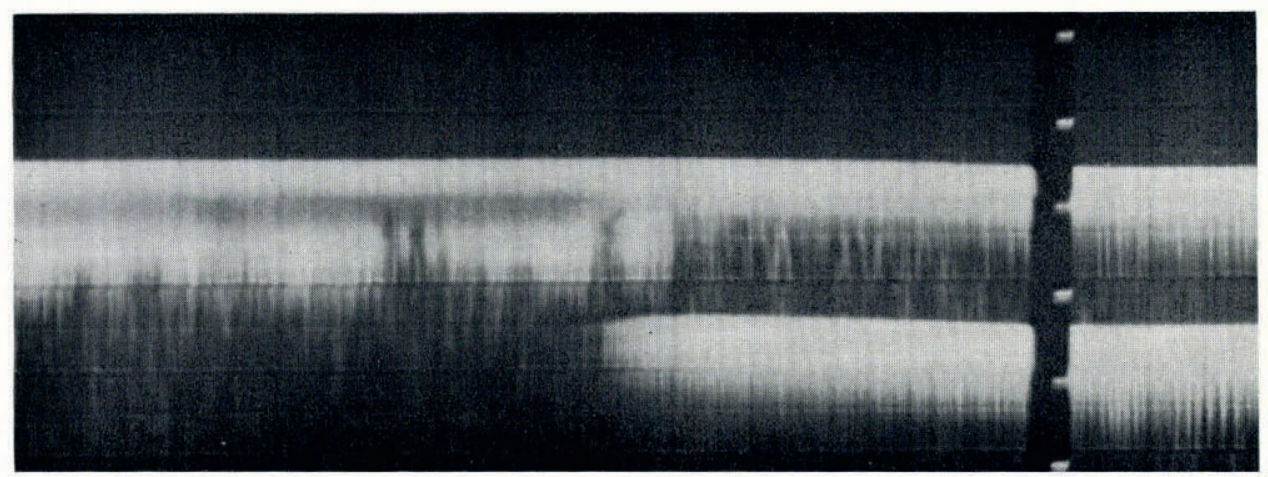

Fig. 5. A section of a radio-echo record obtained on the Larsen Ice Shelf (lat. $68^{\circ} S$., long $60^{\circ} W$.). The range calibration marks are at $I \mu$ s intervals and on the right of the photograph, echoes from the surface and bottom of the ice shelf show it to be $150 \mathrm{~m}$ thick. On the left of the photograph a reflecting layer has appeared at about $45 \mathrm{~m}$ below the ice surface and the bottom echo has been extinguished. Since the surface is flat we suppose that brine has percolated horizontally through the porous upper layers from one of the nearby rifts which contain sea-water. 


\section{RAIN SOAKING}

Rainwater conductivity is two to three orders of magnitude lower than that of sea-water, on the other hand it is possible to imagine that considerable thicknesses of permeable temperate glaciers may be saturated with rain in some seasons. Figure 6 shows two results using the mean rainwater conductivity measured in the vicinity of Norwegian glaciers $\left(\sigma=4 \times \mathrm{rO}^{-3} \Omega^{-1} \mathrm{~m}^{-1}\right)$. For dense snow, absorption due to water conductivity is the dominant mechanism but the loss is not high, about $7 \mathrm{~dB}$ one-way in a $50 \mathrm{~m}$ thickness, because the quantity of water is low. Less dense snow has higher reflexion losses and higher absorption losses reaching a total of about $\mathrm{r} 6 \mathrm{~dB}$ one-way in $5^{\circ} \mathrm{m}$ thickness. It is unlikely that low density snow could be as thick as this and thus absorption due to the bulk conductivity of rain-soaked snow is inadequate to account for the difficulty of sounding temperate glaciers.

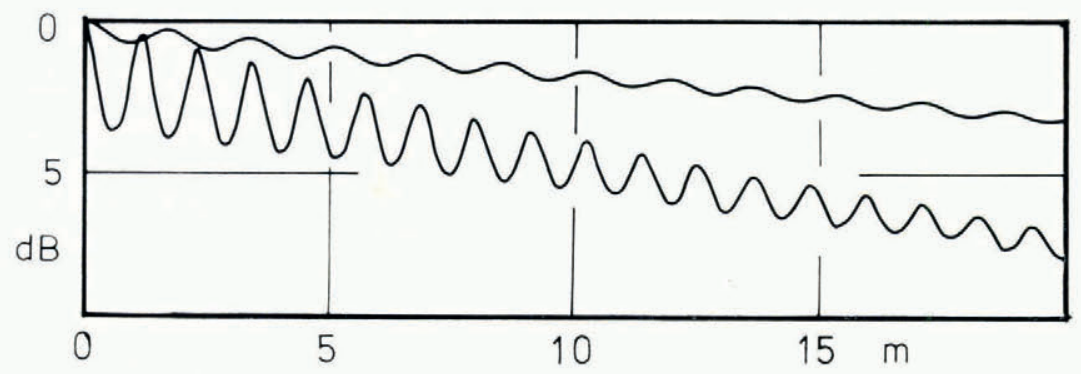

Fig. 6. The attenuation of a $35 \mathrm{MHz}$ wave passing through firn having a layer of rain-soaking $\left(\sigma=4 \times 10^{-3} \Omega^{-1} \mathrm{~m}^{-1}\right)$ as a function of layer thickness. The upper trace (a) applies to firn of density $0.8 \mathrm{Mg} \mathrm{m}^{-3}$, and the lower trace (b) to firn of density $0.5 \mathrm{Mg} \mathrm{m}^{-3}$.

The effect on velocity might be serious however. For the lower density $\left(\rho=0.5 \mathrm{Mg} \mathrm{m}^{-3}\right)$, using Equations $(6)$ and $(7)$, we find $\epsilon_{\mathrm{S}}{ }^{\prime}=15.2$. The ratio of the velocity in the soaked firn to that in ice is $(3.22 / 15.2)^{\frac{1}{2}}=\mathrm{I} / 2.3$, that is to say, if there were $50 \mathrm{~m}$ of soaked firn it might be interpreted as I $15 \mathrm{~m}$ of ice, an error of $65 \mathrm{~m}$. G. de Q. Robin has suggested that variations in bottom-echo delay time, with season, at a fixed point, may be interpreted in terms of variation in water content: this is a promising technique.

\section{Scattering LOSSES}

We have so far ignored the scale of the irregularities present in the mixture models; the formulas for $\epsilon$ and $\sigma$ define their effective values over a volume within which the constituents are very finely divided. Clearly individual inhomogeneities of finite size will scatter some power from the forward wave and for simplicity we shall consider them to be spheres. However unlikely this may be in nature, we shall obtain an answer which should indicate the order of magnitude for other shapes, and give a clear indication of the effect of changing the scale.

An isolated dielectric sphere, radius $b$ permittivity $\epsilon_{1} \epsilon_{0}$ embedded in a medium of permittivity $\epsilon_{2} \epsilon_{0}$, with an incident wave of amplitude $\mathscr{E}_{0}$ becomes an electric dipole of moment (Stratton, I94I, p. 572)

$$
4 \pi b^{3} \epsilon_{2} \epsilon_{0}\left(\frac{\epsilon_{1}-\epsilon_{2}}{\epsilon_{1}+2 \epsilon_{2}}\right) \mathscr{E}_{0} .
$$

Substituting the power radiated by a dipole (Stratton, I94 I, p. 437) and the power flow in 
the incident wave $p_{\mathrm{i}}$, from Equation (4), we find the scattered power $p_{\mathrm{s}}$ from a single spherical inhomogeneity:

$$
p_{\mathrm{S}}=\frac{8}{3} \pi \omega^{4} b^{6}\left(\mu_{0} \epsilon_{2} \epsilon_{0}\right)^{2}\left(\frac{\epsilon_{1}-\epsilon_{2}}{\epsilon_{1}+2 \epsilon_{2}}\right)^{2} p_{\mathrm{i}} .
$$

If there are $m$ similar spheres per unit volume, then the fraction of the power lost from the forward wave per unit length path through the medium is:

$$
\delta=\frac{8 \pi}{3} m b^{6}\left(\frac{2 \pi}{\lambda_{0}}\right)^{4}\left[\frac{\epsilon_{2}\left(\epsilon_{\mathrm{I}}-\epsilon_{2}\right)}{\epsilon_{\mathrm{I}}+2 \epsilon_{2}}\right]^{2} .
$$

The attenuation is $1 \mathrm{O}^{3} \log _{10}(\mathrm{I}-\delta) \mathrm{dB}$ per $\mathrm{r}$ oo $\mathrm{m}=434 \delta \mathrm{dB}$ per $\mathrm{roo} \mathrm{m}$ for $\delta \ll \mathrm{I}$.

Consider three types of inhomogeneity in low density snow, $\rho=0.5 \mathrm{Mg} \mathrm{m}^{-3}$. First, the air bubbles themselves: $\epsilon_{1}=\mathrm{I}$ and $\epsilon_{2}=3.2$.

From $4 \pi b^{3} m / 3=\mathrm{I}-0.5 / 0.92$ we obtain $m b^{3}=\mathrm{IO}^{-1}$. If the radius is $\mathrm{I} \mathrm{mm}$ (a large bubble size) then $m b^{6}=10^{-10}$. The attenuation is

$$
5 \times \mathrm{IO}^{-4} / \lambda_{0}{ }^{4} \mathrm{~dB} \text { per } \mathrm{r} \text { oo } \mathrm{m} \text {. }
$$

This is the same result as obtained by Robin and others (1969) where it was concluded that for bubbles of $\mathrm{I} \mathrm{mm}$ radius or less the attenuation loss is of no practical significance at radio-frequencies less than $\mathrm{I}_{\mathrm{GHz}}\left(\lambda_{0}=0.3 \mathrm{~m}\right)$.

Now consider snow of the same density, $0.5 \mathrm{Mg} \mathrm{m}^{-3}$, but with all holes filled with rainwater. In this case $\epsilon_{2}=3.2$ and $\epsilon_{1} \gg \epsilon_{2}$. The value $m b^{6}=10^{-10}$, the same as above. For bubbles of $\mathrm{I}$ mm radius the attenuation is

$$
5 \times 10^{-3} / \lambda_{0}{ }^{4} \mathrm{~dB} \text { per } 100 \mathrm{~m} \text {. }
$$

Note that the attenuation varies as the cube of bubble size; for a fixed snow density and for the glacier model, if we accept a limit of $\mathrm{Io} \mathrm{dB}$ per $\mathrm{I}$ oo $\mathrm{m}$, this means a minimum freespace wavelength of $0.15 \mathrm{~m}$.

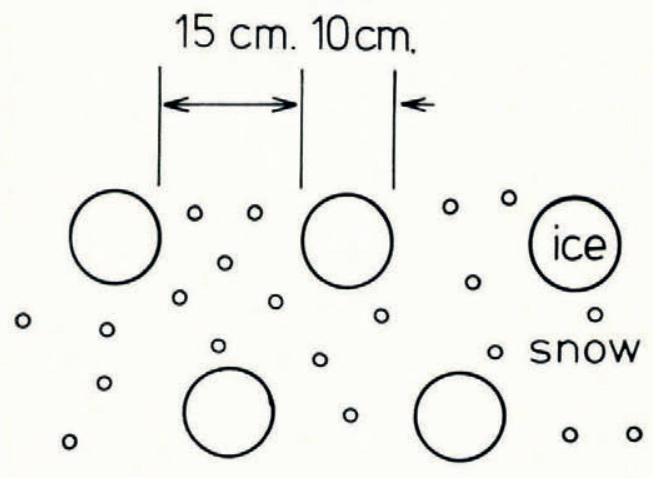

Fig. 7. To illustrate spherical ice "lenses" of radius $50 \mathrm{~mm}$, spaced $250 \mathrm{~mm}$ between centres, in firn.

Finally, since it has appeared that the linear dimensions of the inhomogeneity are allimportant, let us consider that the low density snow may contain the equivalent of spherical ice "lenses" with a radius of $50 \mathrm{~mm}$ at a spacing of $250 \mathrm{~mm}$ as illustrated in Figure 7 . Then $m b^{6}=\mathrm{IO}^{-6}, \epsilon_{\mathrm{I}}=3.2$, and $\epsilon_{2}=2.0$.

The attenuation reduces to

$$
7 \times 1 \mathrm{IO}^{-1} / \lambda_{\mathrm{o}}{ }^{4} \mathrm{~dB} \text { per } 100 \mathrm{~m} \text {. }
$$

This is a dense system of irregularities to which our equations for single scattering hardly apply and it seems improbable in nature, perhaps useful as a limiting case. The numerical result is somewhat more of a restriction on minimum wavelength than the rain-filled bubbles 
in Equation (15). An increasingly dense arrangement of ice lenses might tend to become more homogeneous by the filling of the majority of the surrounding snow medium, and larger individual lenses are likely to be extended in a horizontal plane for which it is more realistic to use the three-layer models discussed earlier.

Figure 8 shows the total attenuation in a single extended horizontal layer of solid ice lying within a snow medium. The systematic downward slope from left to right is due to absorption, and the oscillation is due to reflexion of power at the upper and lower boundaries; this is obviously greater when the density discontinuity is greater, and the first maximum in absorption occurs when the layer is a quarter wavelength thick. For layers of the order of $\mathrm{I} \mathrm{m}$ thickness, it can be seen that the attenuation is typically $0.2 \mathrm{~dB}$ at $35 \mathrm{MHz}$ and there might be $5^{\circ}$ such layers in the top $5^{0} \mathrm{~m}$ of the glacier, giving rise to ro $\mathrm{dB}$ one-way attenuation-easily tolerable in the glacier model. Because of the roughly proportional relation between layer thickness and attenuation seen in Figure 8, it follows that a greater number of thin layers, within the same total depth, would produce the same total attenuation. However, in all cases the attenuation due to reflexion increases proportionally with increasing radio frequency, until individual layers become $\approx \lambda_{\mathrm{i}} / 4$. Thus at $500 \mathrm{MHz}$, ice layers of $50 \mathrm{~mm}$ thickness in low density snow each contribute $0.2 \mathrm{~dB}$ to the one-way attenuation, and this could become prohibitive.

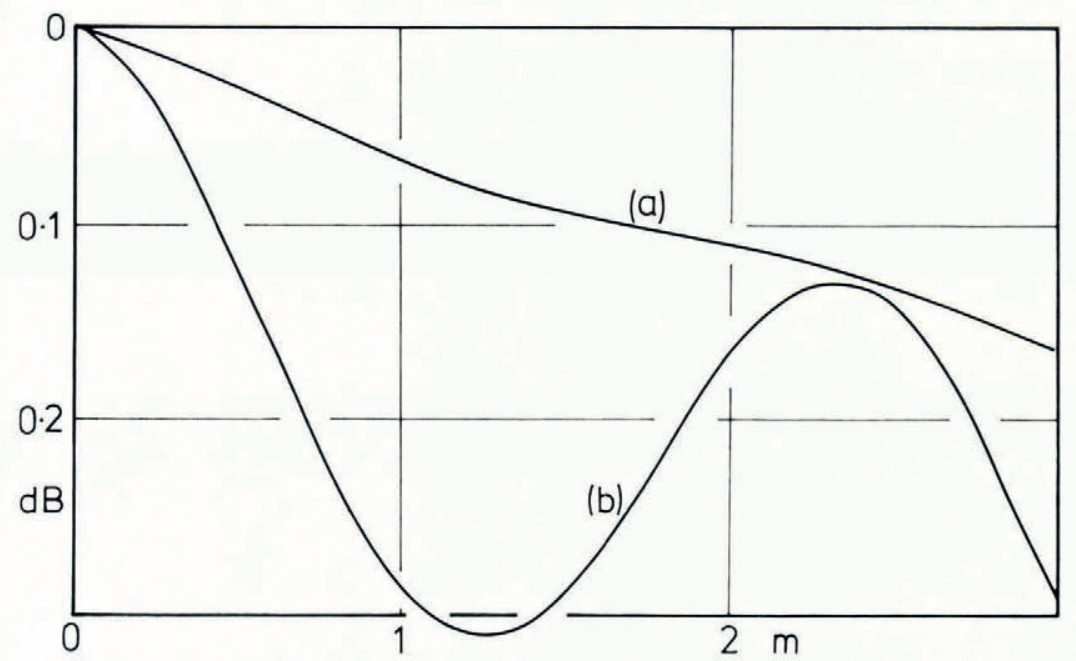

Fig. 8. The attenuation in $d B$ of a $35 \mathrm{MHz}$ wave passing one way through a layer of ice $\left(\rho=0.92 \mathrm{Mg} \mathrm{m}^{-3}, \sigma=6 \times 1 \mathrm{O}^{-}\right.$, $\left.\Omega^{-1} \mathrm{~m}^{-1}\right)$ lying within a firn medium, as a function of layer thickness, for two different firn densities $(a)$ o.8 $\mathrm{Mg} \mathrm{m}^{-35}$ (b) $0.5 \mathrm{Mg} \mathrm{m}^{-3}$.

\section{BACKGROUND SIGNAL DUE TO SCATTER ECHOES}

At frequencies below $500 \mathrm{MHz}\left(\lambda_{0}=0.67 \mathrm{~m}\right)$ none of the mechanisms so far considered presents any practical obstacle in the way of the forward power. Therefore consider how the scattered power returned to the receiver at any instant compares with the wanted echo signal from the glacier bottom. The product of the transmitter pulse duration and the propagation velocity in the medium defines a pulse length $l$. At any instant after transmission, power is received from a shell of thickness $l / 2$ and range $r$. If the antenna power gain is $g$, the effective volume from which scattered echo power is received is $2 \pi r^{2} l / g$. There are $m$ scattering centres per unit volume and each has backward scattering gain, as an elementary dipole, of r.6. The relative phase of each, at the receiver, is random. Hence 


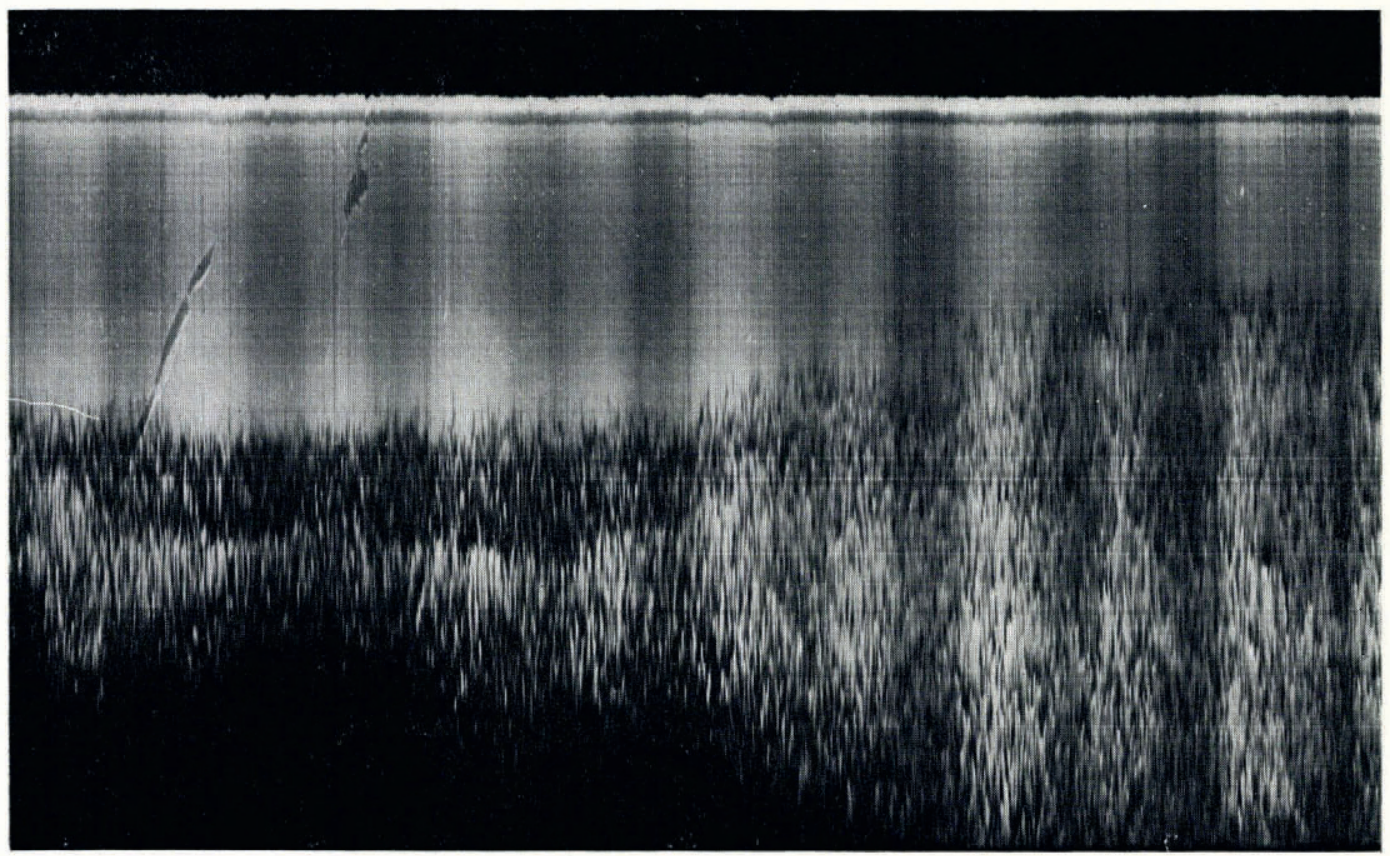

(a)

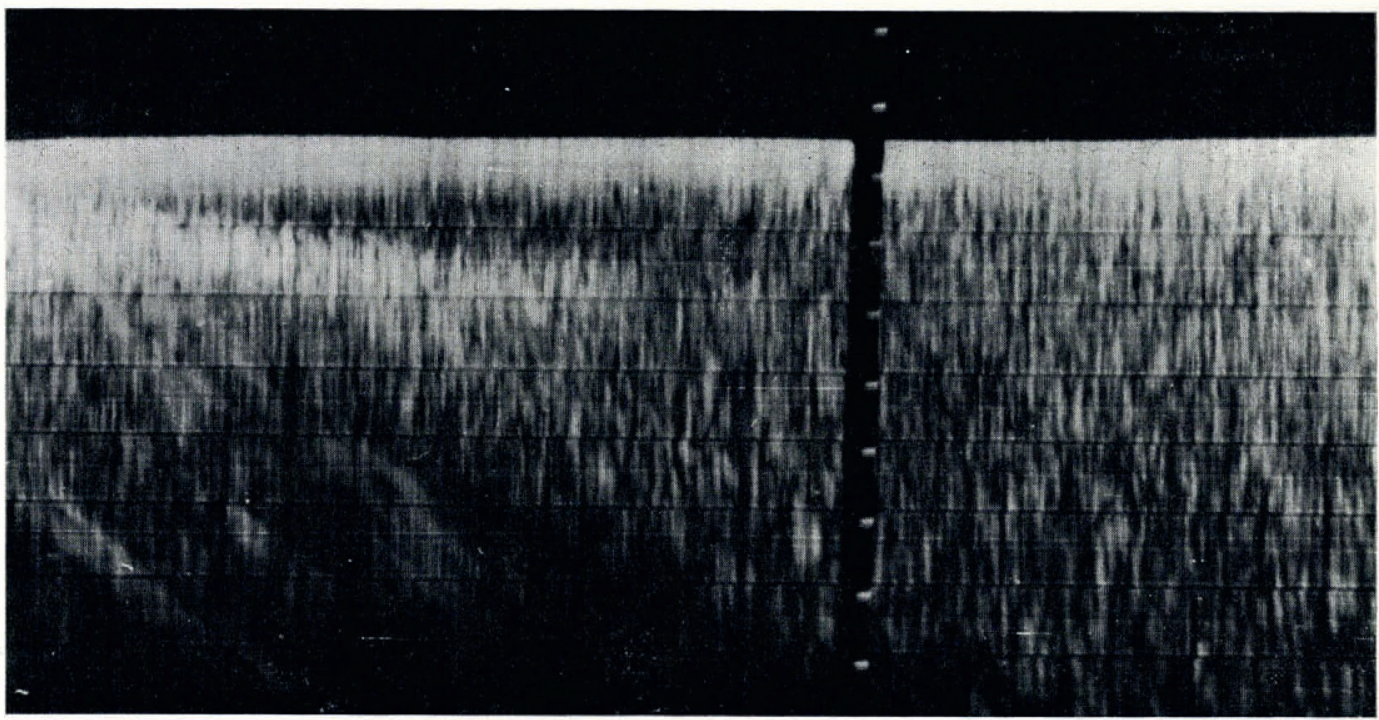

(b)

Fig. 9. Radio-echo sounding records showing the bottom echo disappearing into scatter echoes. The upper record (a), courtesy of Randall Electronics Ltd., was obtained on Hardangerjokulen, Norway, using a $480 \mathrm{MHz}$ sounder on the surface. The bottom echo, to the left, is at a depth of $100 \mathrm{~m}$ and it disappears into the scatter echoes to the right.

The lower record $(b)$ was obtained on the Fuchs Ice Piedmont, Adelaide Island, Antarctica using a $35 \mathrm{MHz}$ sounder in an aircraft. In this case we suppose that the scatter echoes to the right are due to sufficiently large ice lenses, each one extending horizontally not more than a few metres because of the observed fading. The bottom echo is $40 \mathrm{~d} B$ above the receiver input noise level but it is nevertheless lost in the centre of the picture at $150 \mathrm{~m}$ depth. 
the individual powers add, and let the receiver antenna cross-section be $s$. The total power received from the scattering centres in the effective volume is

$$
p_{\mathrm{r}}(\text { scattered })=\frac{2 \pi r^{2} l}{g} \frac{\mathrm{r} \cdot 6 m s}{4 \pi r^{2}} p_{\mathrm{s}} .
$$

The power $p_{\mathrm{s}}$ from a single centre, is given by Equation (12); the incident power is $p_{\mathrm{i}}=p_{\mathrm{t}} g / 4 \pi r^{2}$ and the cross-section $s=g \lambda_{0}{ }^{2} / 4 \pi$ if the receiver and transmitter antennas are similar, and in air.

Hence

$$
\frac{p_{\mathrm{r}}(\text { scattered })}{p_{\mathrm{t}}}=\frac{64 \pi^{3} g l}{3 \mathrm{O} r^{2} \lambda_{0}^{2}}\left[\frac{\epsilon_{2}\left(\epsilon_{1}-\epsilon_{2}\right)}{\epsilon_{\mathrm{I}}+2 \epsilon_{2}}\right]^{2}{ }^{2} m b^{6} .
$$

If the power reflexion coefficient of a plane reflector at the same range is $R$, the echo power received from the plane is given by

$$
\frac{p_{\mathrm{r}}(\text { plane })}{p_{\mathrm{t}}}=g^{2} \lambda_{0}^{2} R / 64 \pi^{2} r^{2} .
$$

The signals will also be attenuated by absorption in the medium but this will be the same for both, at the same range, and the ratio of the plane (wanted) to the scattered (unwanted) echo reduces to:

$$
\frac{\left.p_{\mathrm{r}} \text { (plane }\right)}{p_{\mathrm{r}}(\text { scattered })}=\frac{6 \times 10^{-6} g \lambda_{0}{ }^{4} R}{\operatorname{lm} b^{6}}\left[\frac{\epsilon_{1}+2 \epsilon_{2}}{\epsilon_{2}\left(\epsilon_{1}-\epsilon_{2}\right)}\right]^{2} .
$$

Thus the difference between the two echo powers, $E_{\mathrm{p}}$ and $E_{\mathrm{s}}$ expressed in $\mathrm{dB}$ relative to the receiver input noise power, as in Robin and others (1969) is $E_{\mathrm{p}}-E_{\mathrm{s}}=P+R-C$. The factor $P$ includes the relevant equipment parameters. For the SPRI Mk II equipment (Evans and Smith, I969) $\lambda_{0}=8.6 \mathrm{~m}, g \approx 2$, and $l=40 \mathrm{~m}$, from which $P=-28 \mathrm{~dB}$. $R$ is the reflexion coefficient of the plane surface; let us take $-20 \mathrm{~dB}$. $C$ includes the properties of the scatterers. For the rain-filled bubbles in Equation (I5) $C=-90 \mathrm{~dB}$, while for the ice lenses in Equation (17) $C=-69 \mathrm{~dB}$; thus we can expect to cope with this particular ice lens model. However there is only a modest margin of safety and note should be taken of the two crucial factors in signal to scatter ratio: radio wavelength and effective lens radius. This is a new situation in which increased system performance will do nothing to improve the ratio. The penalty for reducing wavelength is not so severe as it appears at first sight because one can expect $g \lambda_{0}{ }^{2}$ to be approximately constant, for a constant antenna area, and one can hope to reduce $l$ proportional to $\lambda_{0}$ with increasing resolution as a bonus. Figure 9 shows two examples of scatter echoes, one at $35 \mathrm{MHz}$ supposed to be from ice lenses on Adelaide Island, Antarctica, and one at $500 \mathrm{MHz}$ from rain-soaked firn on Hardangerjøkulen, Norway. Probably multiple scattering occurs in both cases, and since the scatter echoes extend to ranges greater than that of the bottom echo, we assume that they originate from a wide range of angles. It is to be expected that scattering from lenses of large horizontal extent will be more specular, will have characteristic layer structure, and will weaken rather quickly at ranges no greater than the bottom echo. Simultaneous measurements at different radio frequencies are now in progress on an Alpine glacier to test some of these results.

\section{Acknowledgements}

Radio-echo work at the Scott Polar Research Institute has been supported by a grant from the Natural Environment Research Council. We are grateful for logistic support in 
the field from a number of organizations including: British Antarctic Survey, Canadian Defence Research Board, U.S. National Science Foundation, Norges Vassdrags- og Elektrisitetsvesen, and Versuchsanstalt für Wasserbau und Erdbau, Zürich, Switzerland.

MS. received 27 February 197 I and in revised form I June 197 I

\section{REFERENCES}

Addison, J. R. 1970. Electrical relaxation in saline ice. Fournal of Applied Physics, Vol. 41, No. 1, p. 54-63.

Bialek, E. L., comp. [1967.] Handbook of oceanographic tables, 1966. (Special publication.) Washington, D.C., U.S. Naval Oceanographic Office.

Davis, J. L., and Halliday, J. S. Unpublished. Radio echo sounding on the Roslin glacier, Greenland.

Dubrovin, L. I. I 962 . O rassolakh v shel'fovykh lednikakh [Brine in ice shelves]. Informatsionnyy Byulleten' Sovetskoy Antarkticheskoy Ekspeditsii, No. 35, p. 35-38.

Egner, H., and Eriksson, E. I955. Current data on the chemical composition of air and precipitation. Tellus, Vol. 7, No. 1, p. 134-39.

Evans, S., and Smith, B. M. E. 1969. A radio echo equipment for depth sounding in polar ice sheets. Fournal of Scientific Instruments (Journal of Physics, E), Ser. 2, Vol. 2, No. 2, p. 13 $1-36$.

Fujino, K. 1967. Kaihyō no yūdenteki seishitsu ni kansuru kenkyū [Dielectric properties of sea ice]. Teionkagaku: Low Temperature Science, Ser. A, [No.] 25, p. 127-69.

Gorham, E. 1958. Soluble salt in a temperate glacier. Tellus, Vol. 10, No. 4, p. 496-97.

Hasted, J. B. 196i. The dielectric properties of water. Progress in Dielectrics, Vol. 3, p. 101-49.

Heine, A. J. r968. Brine in the McMurdo Ice Shelf, Antarctica. New Zealand Fournal of Geology and Geophysics, Vol. I I, No. 4, p. 829-39.

Nye, J. F., and Frank, F. C. In press. The hydrology of the intergranular veins in a temperate glacier. Union Géodésique et Géophysique Internationale. Association Internationale d'Hydrologie Scientifique. Commission de $\mathcal{N}_{\text {eiges }}$ et Glaces. Symposium on the hydrology of glaciers, Cambridge, $7^{-1} 3$ September 1969, organized by the Glaciological Society.

Paren, J. G. Unpublished. Dielectric properties of ice. [Ph.D. thesis, University of Cambridge. 1970.]

Paren, J. G., and Walker, J. C. F. 1971. Limited solubility in ice: its influence on electrical and mechanical properties. Nature, Physical Science, Vol. 230, No. 12, p. 77-79.

Robin, G. de Q., and others. 1969 . Interpretation of radio echo sounding in polar ice sheets, by G. de Q. Robin, S. Evans and J. T. Bailey. Philosophical Transactions of the Royal Society, Vol. 265A, No. 1 166, p. 437-505.

Röthlisberger, H. ${ }^{1967 . ~ E l e c t r i c a l ~ r e s i s t i v i t y ~ m e a s u r e m e n t s ~ a n d ~ s o u n d i n g s ~ o n ~ g l a c i e r s: ~ i n t r o d u c t o r y ~ r e m a r k s . ~}$ Fournal of Glaciology, Vol. 6, No. 47, p. 599-6o6.

Smith, B. M. E. In press. Airborne radio echo sounding of glaciers in the Antarctic Peninsula. British Antarctic Survey. Scientific Reports, No. 72.

Stratton, J. A. 1941. Electromagnetic theory. New York and London, McGraw-Hill Book Co.

Swithinbank, C. W. M. I968. Radio echo sounding of Antarctic glaciers from light aircraft. Union de Géodésie et Géophysique Internationale. Association Internationale d'Hydrologie Scientifique. Assemblée générale de Berne, 25 sept.7 oct. 1967. [Commission de Neiges et Glaces.] Rapports et discussions, p. 405-14.

Swithinbank, C. W. M. I970. Ice movement in the McMurdo Sound area of Antarctica. [Union Géodésique et Géophysique Internationale. Association Internationale d'Hydrologie Scientifique.] [International Council of Scientific Unions. Scientific Committee on Antarctic Research. International Association of Scientific Hydrology. Commission of Snow and Ice.] International Symposium on Antarctic Glaciological Exploration (ISAGE), Hanover, New Hampshire, U.S.A., 3-7 September 1968 , p. $472-87$. 